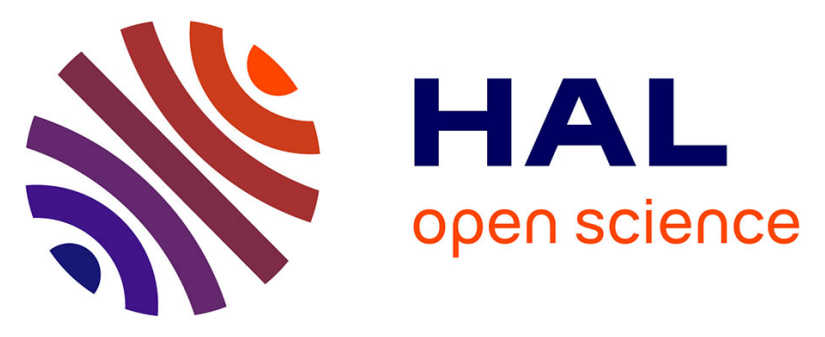

\title{
Teaching an old molecule new tricks Evidence and rationalisation of the slow magnetisation dynamics in [DyTp2Acac]
}

Frédéric Guégan, François Riobé, Olivier Maury, Julie Jung, Boris Le

Guennic, Christophe Morell, Dominique Luneau

\section{To cite this version:}

Frédéric Guégan, François Riobé, Olivier Maury, Julie Jung, Boris Le Guennic, et al.. Teaching an old molecule new tricks Evidence and rationalisation of the slow magnetisation dynamics in [DyTp2Acac]. Inorganic Chemistry Frontiers, 2018, 5 (6), pp.1346-1353. 10.1039/c8qi00174j . hal-01835016

\section{HAL Id: hal-01835016 https://hal-univ-rennes1.archives-ouvertes.fr/hal-01835016}

Submitted on 13 Jul 2018

HAL is a multi-disciplinary open access archive for the deposit and dissemination of scientific research documents, whether they are published or not. The documents may come from teaching and research institutions in France or abroad, or from public or private research centers.
L'archive ouverte pluridisciplinaire HAL, est destinée au dépôt et à la diffusion de documents scientifiques de niveau recherche, publiés ou non, émanant des établissements d'enseignement et de recherche français ou étrangers, des laboratoires publics ou privés. 


\title{
Teach an old molecule new tricks: evidence and rationalisation of a slow dynamics of magnetisation in $\left[\mathrm{DyTp}_{2} \mathrm{Acac}\right]^{\dagger}$
}

\author{
Guégan Frédéric ${ }^{1,2, *, \ddagger}$, Riobé François ${ }^{3}$, Maury Olivier ${ }^{3}$, Jung Julie ${ }^{4}$, Le Guennic Boris ${ }^{4}$, \\ Morell Christophe ${ }^{2}$ and Luneau Dominique ${ }^{1, *}$
}

1 Univ Lyon, Université Claude Bernard Lyon 1, CNRS, Laboratoire des Multimatériaux et Interfaces, F-69622, Villeurbanne, France.

$\ddagger$ Present address: Sorbonne Université, CNRS, Laboratoire de Chimie Théorique, LCT, F-75005 Paris, France.

2 Univ Lyon, Université Claude Bernard Lyon 1, ISA (Institut des Sciences Analytiques de Lyon) - CNRS UMR 5280, F-69100, Villeurbanne, France.

3 Univ Lyon, Ens de Lyon, CNRS UMR 5182, Université Claude Bernard Lyon 1, Laboratoire de Chimie, F69342 Lyon, France.

4 Univ Rennes, CNRS, ISCR (Institut des Sciences Chimiques de Rennes) - UMR 6226, F-35000 Rennes, France. 


\section{S1 Introduction}

Lanthanide-based complexes have been at the heart of a tremendous research effort in the last decades, because of the original physical properties they may present. ${ }^{1,2}$ Their incomplete $4 f$ electronic shells indeed give them, for instance, a propensity to display visible or near-IR luminescence, ${ }^{3,4}$ as well as strong magnetic anisotropies that may result in a Single Molecule Magnet (SMM) character. ${ }^{5,6}$ Actually, as suggested by Van Vleck in a seminal article, ${ }^{7}$ these luminescence and magnetic properties are strongly coupled since both origin from the crystal (ligand)-field splitting of their $4 f$ orbitals. We have been interested for long in such correlation between magnetism and luminescence, and it has been exemplified several times within the past ten years. ${ }^{8-22}$

Furthermore, lanthanide single ion anisotropies are strong enough to permit the observation of a SMM behaviour even for mononuclear complexes, provided naturally that quantum tunnelling of magnetisation (QTM) is not too effective. ${ }^{23}$ These mononuclear SMM are very interesting from a fundamental point of view. Because of their relative simplicity, they indeed offer the possibility to deduce relationships between the molecular structure and the observation of a slow dynamics of magnetisation; one may noteworthy think of Rinehart and Long's model. ${ }^{24}$ The interest is also practical, in the sense that such models may allow to synthesise lanthanide complexes with tailored magnetic and luminescent properties, which could be used for molecular spintronics, quantum computing, magnetic refrigeration and in lighting devices for instance. ${ }^{25-29}$

Yet, it lately appeared that these models are often too limited to be fully predictive. ${ }^{30-32}$ They indeed focus only on the single-molecule level, whereas it is known that relaxation of magnetisation is a much more complex phenomenon, stemming from the spin-phonon and spin-spin interactions in the solid. ${ }^{33,34}$ As a result, multiple relaxation processes may be active, ${ }^{30}$ and in such cases the use of luminescence spectroscopy can bring valuable information, as it may allow to access the low energy diagram of lanthanide complexes and to critically discuss the apparent energy barriers for the reversal of magnetisation. ${ }^{8-13}$

In this publication, we report the characterisation of such multiple-processes slow dynamics of magnetisation in a Dy(III) mononuclear complex, [DyTp 2 Acac] (with Tp = tris-pyrazolylborohydride, ${ }^{35}$ Acac $=2,4$-pentanedionate). Its synthesis was reported thirty years ago, ${ }^{36}$ but to our best knowledge its spectroscopic and magnetic properties remained unstudied. As we show, in the absence of a static field the slow dynamics of $\left[\mathrm{DyTp}_{2} \mathrm{Acac}\right]$ is rather simple but original. Using a combination of luminescence spectroscopy and magnetic measurements, with the support of ab initio calculations, we tentatively assign the slow relaxation processes, and show they likely stem from QTM and Raman processes, rather than from the expected Orbach activation model.

\section{S2 Syntheses and structures.}

[DyTp $\mathrm{D}_{2}$ Acac] was synthesised according to a slightly modified version of the previously published procedure: ${ }^{36}$ the complex was obtained by a simple mixture of methanolic solutions of the Tp and Acac ligands and $\mathrm{DyCl}_{3} \cdot 6 \mathrm{H}_{2} \mathrm{O}$, and isolated by recrystallisation.

This afforded [DyTp 2 Acac] as well-defined single crystals, which proved to be suitable for single-

crystal X-Ray diffraction studies. The crystallographic parameters are recalled in Table S1, and the structure of the asymmetric unit is depicted on Figure S1. The structure is in full agreement with the previous X-Ray analysis on the $\left[\mathrm{LnTp}_{2} \mathrm{Acac}\right]$ complexes. ${ }^{36}$

Accordingly, the coordination geometry around the Dy(III) ion can be described as being a distorted bicapped trigonal prism, formed by 2 oxygen atoms from the $\beta$-diketonate ligand ${ }^{37,38}$ and 6 nitrogen atoms from 2 Tp ligands. ${ }^{39}$ Interestingly, no obvious intermolecular H-bond nor $\pi$ stacking interactions are found in the crystal packing, and the shortest Dy-Dy distance is found to 
be $9.0195(3) \AA$. As such, the complexes may at first be considered as isolated in the crystal state.

Table S1: Cell and refinement parameters for the single crystal X-ray (Mo $\mathrm{K} \alpha, \lambda=0.71073 \AA$ ) diffraction study of [DyTp $\left.\mathrm{D}_{2} \mathrm{Acac}\right] . \mathrm{N}_{I R} / \mathrm{N}_{R \cdot R}$ : number of independent reflections versus number of refined reflections.

\begin{tabular}{l|l}
\hline Formula & {$\left[\mathrm{DyTp}_{2}\right.$ Acac $]$} \\
$\mathrm{FW}\left({\left.\mathrm{g} . \mathrm{mol}^{-1}\right)}^{-1}\right.$ & 687.67 \\
\hline$a(\AA)$ & $15.2071(5)$ \\
$b(\AA)$ & $12.8077(4)$ \\
$c(\AA)$ & $14.8944(5)$ \\
\hline$\alpha, \gamma\left({ }^{\circ}\right)$ & 90 \\
$\beta\left(^{\circ}\right)$ & $102.117(3)$ \\
$V\left(\AA^{3}\right)$ & $2836.3(2)$ \\
$Z$ & 4 \\
\hline Space group & $\mathrm{P} 2_{1} / \mathrm{c}$ \\
$\mu\left(\mathrm{cm}^{-1}\right)$ & 2.679 \\
$\mathrm{~F}_{000}$ & 1364 \\
$\mathrm{~N}_{I . R} / \mathrm{N}_{R . R}$ & $7034 / 5007$ \\
$\mathrm{~N} . \mathrm{parameters}$ & 361 \\
$R(F, I>3 \sigma(I))$ & $5.09 \%$ \\
$R w(F, I>3 \sigma(I))$ & $4.73 \%$ \\
GooF & 1.1815 \\
\hline
\end{tabular}

\section{S3 Luminescence measurements}

In Figure S2, we represent the solid state luminescence spectrum of [DyTp $2 A c a c]$ in the $400 \mathrm{~nm}-$ $700 \mathrm{~nm}$ range, as measured under a $350 \mathrm{~nm}$ excitation. As one can notice, an intense luminescence is observed at room temperature featuring the characteristic profile of Dy(III) emission. ${ }^{11,40-42}$

The two first bands around 480 and $580 \mathrm{~nm}$ are assigned to ${ }^{4} F_{9 / 2} \rightarrow{ }^{6} H_{15 / 2}$ and ${ }^{4} F_{9 / 2} \rightarrow{ }^{6} H_{13 / 2}$ electronic transitions of Dy(III), respectively. ${ }^{3,40}$ The luminescence decay is well fitted by a monoexponential function, leading to a $31.4(4) \mu \mathrm{s}{ }^{4} F_{9 / 2}$ excited state lifetime at room temperature (cf. Figure S4 in SI).

Lowering the temperature down to $77 \mathrm{~K}$ and $10 \mathrm{~K}$ affords more resolved emission and excitation spectra, as shown in Figure S3. Interestingly, their combined analyses enable the determination of the complete energy diagrams of both the ground $\left({ }^{6} H_{15 / 2}\right)$ and emitting $\left({ }^{4} F_{9 / 2}\right)$ states. It is worth noting that for low symmetry Dy(III) complexes the crystal field splitting of the ${ }^{6} H_{15 / 2}$ and ${ }^{4} F_{9 / 2}$ levels should result, at most, in 8 and 5 Kramers doublets (KD), respectively. ${ }^{3,40}$ Additional transitions are nevertheless quite often observed, and are generally assigned to vibronic or "hot bands" contributions. ${ }^{7,13,14}$

In the present case, the excitation spectrum (see Figure S3) is composed of five main transitions at 21146(9), 21209(9), 21317(9), 21432(9) and 21505(9) $\mathrm{cm}^{-1}$, corresponding to transitions from the lowest $\mathrm{KD}$ of ${ }^{6} \mathrm{H}_{15 / 2}$ towards the five KDs of ${ }^{4} F_{9 / 2}$, and of five less intense bands corresponding to hot bands from the ground state (transition from higher energy KDs). At $77 \mathrm{~K}$ the emission spectrum is more difficult to assign because 10-14 transitions accompanied by shoulders are present, due to the remaining presence of hot bands at this temperature. Further decrease of the temperature to $10 \mathrm{~K}$ results in the disappearance of the hot bands thanks to the thermal depopulation of the 


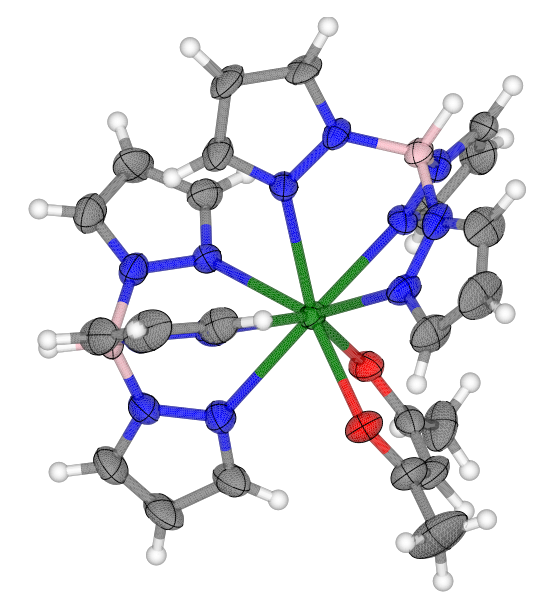

Figure S1: ORTEP drawing of the [DyTp 2 Acac] complex (ellipsoids drawn at $50 \%$ probability). Colour scheme: blue, N; gray, C; green, Dy; pink, B; red, O; white, H.

excited state KDs, and expectedly 8 transitions are clearly visible at 20479(8), 20611(8), 20742(8), 20803(8), 20858(9), 20929(9), 21006(9) and 21145(9) $\mathrm{cm}^{-1}$, respectively.

As a result, it is here possible to deduce the energy splitting patterns in both the ${ }^{6} H_{15 / 2}$ (see Figure S6) and ${ }^{4} F_{9 / 2}$ levels. In this case, the energy splitting between the first and second KD of the ${ }^{6} H_{15 / 2}$ ground state can be estimated to $139(18) \mathrm{cm}^{-1}$ (and the total energy span of the multiplet is $666(17) \mathrm{cm}^{-1}$ ). This value is comparable to the reported energy splitting of the majority of Dy(III)-based SMM. ${ }^{13,14,43,44}$ It is thus anticipated that [DyTp 2 Acac] may present a SMM behaviour. However one cannot be peremptory, as energy splitting is far from being the only parameter to master in order to induce a slow relaxation of magnetisation. In the following we will see that this is indeed the case here.

\section{S4 Magnetic properties}

\section{S4.1 Static field measurements}

We report in Figure S4 the thermal dependence of the magnetic susceptibility and the field dependence of magnetisation of [DyTp $\left.\mathrm{D}_{2} \mathrm{Acac}\right]$, as measured on a powder sample. A monotonous decrease is seen in the $\chi T=f(T)$ curve, which may be assigned to the progressive depopulation of the KD of the Dy(III) ion. ${ }^{41,43}$ Indeed, we remind that no obvious intermolecular interactions are seen in the solid state, and the shortest Dy-Dy distance in the lattice is likely too large (above $9 \AA$ ) to allow a significant antiferromagnetic dipolar coupling. Furthermore, the modeled $\chi T=f(T)$ curve from the $a b$ initio calculation on an isolated $\left[\mathrm{DyTp}_{2} \mathrm{Acac}\right]$ molecule shows a sound agreement with the experimental data, suggesting intermolecular magnetic interactions should be very weak.

Noteworthy, the room temperature value of the $\chi T$ product is in the expected range for a single Dy(III) ion: $13.5 \mathrm{~cm}^{3} \cdot \mathrm{K} \cdot \mathrm{mol}^{-1}$, to be compared to the expected free ion value of $14.2 \mathrm{~cm}^{3} \cdot \mathrm{K} \cdot \mathrm{mol}^{-1} \cdot{ }^{45}$

On the other hand, magnetisation at $2 \mathrm{~K}$ displays a rather fast saturation with field (below $2 \times 10^{4} \mathrm{Oe}$ ), and to a rather low value for a Dy(III) ion, ca. $4.86 \mu_{B}$. Together, these features suggest [DyTp $\left.{ }_{2} \mathrm{Acac}\right]$ may present a rather strong magnetic anisotropy, as could be expected for a Dy(III) ion complex. This, in addition to the efficient energy splitting of all the doublets in the ground ${ }^{6} H_{15 / 2}$ state evidenced by luminescence spectroscopy, point towards a potential SMM behaviour for $\left[\mathrm{DyTp}_{2} \mathrm{Acac}\right]$. 


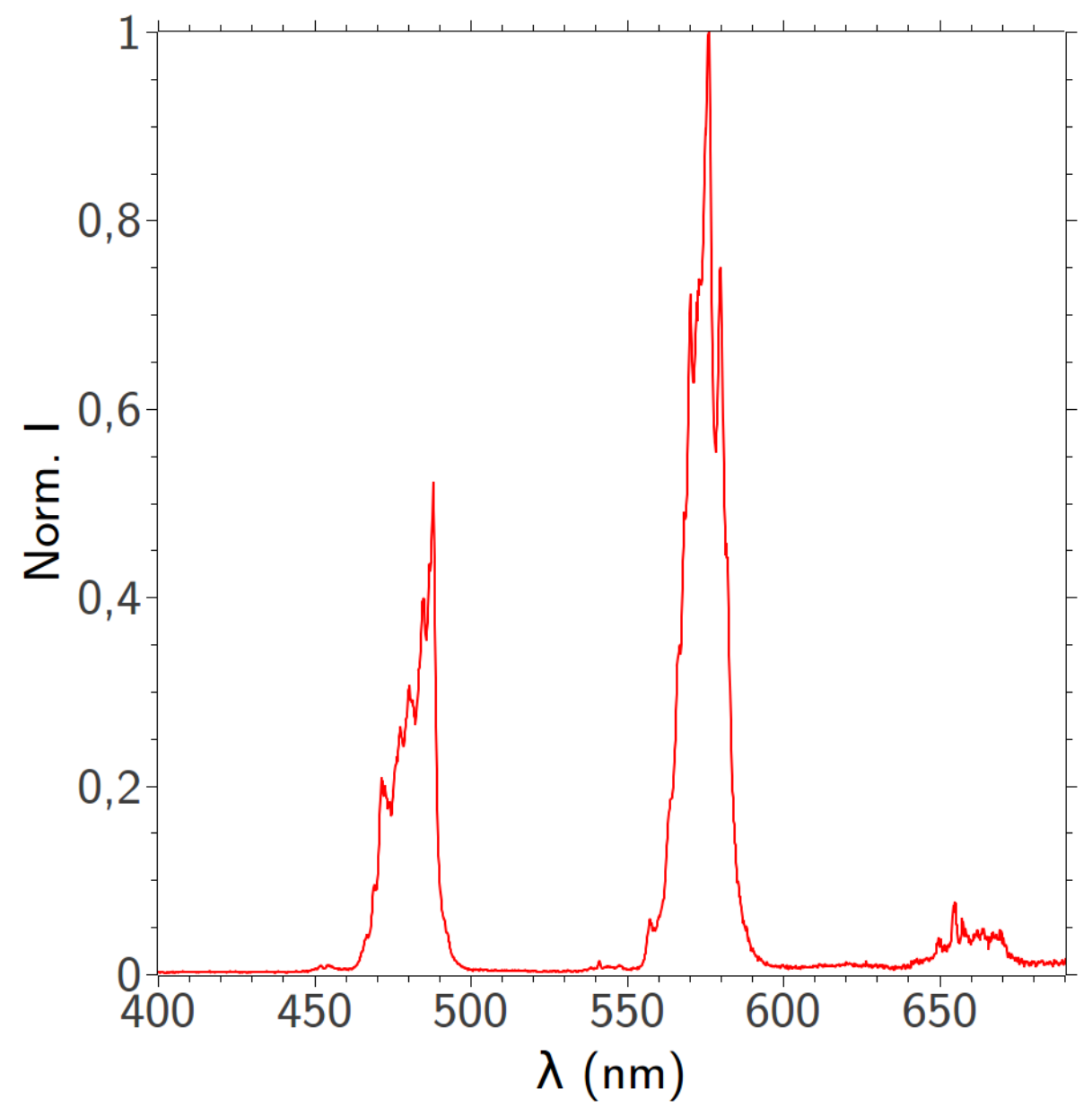

Figure S2: Room temperature solid state luminescence spectrum of [DyTp $\mathrm{DAcac}_{2}\left(\lambda_{e x}=350 \mathrm{~nm}\right)$.

\section{S4.2 AC magnetometry}

We thus studied the dynamics of magnetisation of this complex by the means of AC SQUID magnetometry. An out-of-phase signal is observed in the absence of a static field, as shown on Figure S5. This indicates that quantum tunnelling of magnetisation (QTM) is sufficiently slowed down in this complex. Nevertheless, no maximum can be seen from the $\chi^{\prime \prime}=f(T)$ curves, which implies that relaxation of magnetisation is still quite fast, and this may be due to QTM. ${ }^{1}$ From the almost perfect semi-circular shape of the Cole-Cole $\chi^{\prime \prime}=f\left(\chi^{\prime}\right)$ plots, we may furthermore state that the distribution of relaxation times is narrow. Fitting with a modified Debye equation ${ }^{46}$ yields distortion parameters $\alpha$ ranging from $0.09(1)$ at $2 \mathrm{~K}$ to $0.05(1)$ at $8 \mathrm{~K}$, in good agreement with this statement (fitted parameters can be found in Table S4 in SI).

In order to gain a deeper insight on this slow relaxation of magnetisation, we then employed a previously reported method to fit the $\chi^{\prime \prime}=f(\nu)$ curves at constant temperature, ${ }^{47}$ according to

$$
\chi^{\prime \prime}=\left(\chi_{T}-\chi_{S}\right) \frac{(2 \pi \nu \tau)^{1-\alpha} \cos (\pi \alpha / 2)}{1+2(2 \pi \nu \tau)^{1-\alpha} \sin (\pi \alpha / 2)+(2 \pi \nu \tau)^{2-2 \alpha}},
$$

\footnotetext{
${ }^{1}$ This is further supported by the drastic change in the $1 \mathrm{~Hz} \chi^{\prime}=f(T)$ and $\chi^{\prime \prime}=f(T)$ curves when a static field of 500 Oe is applied, as depicted on Figure S3 in SI.
} 

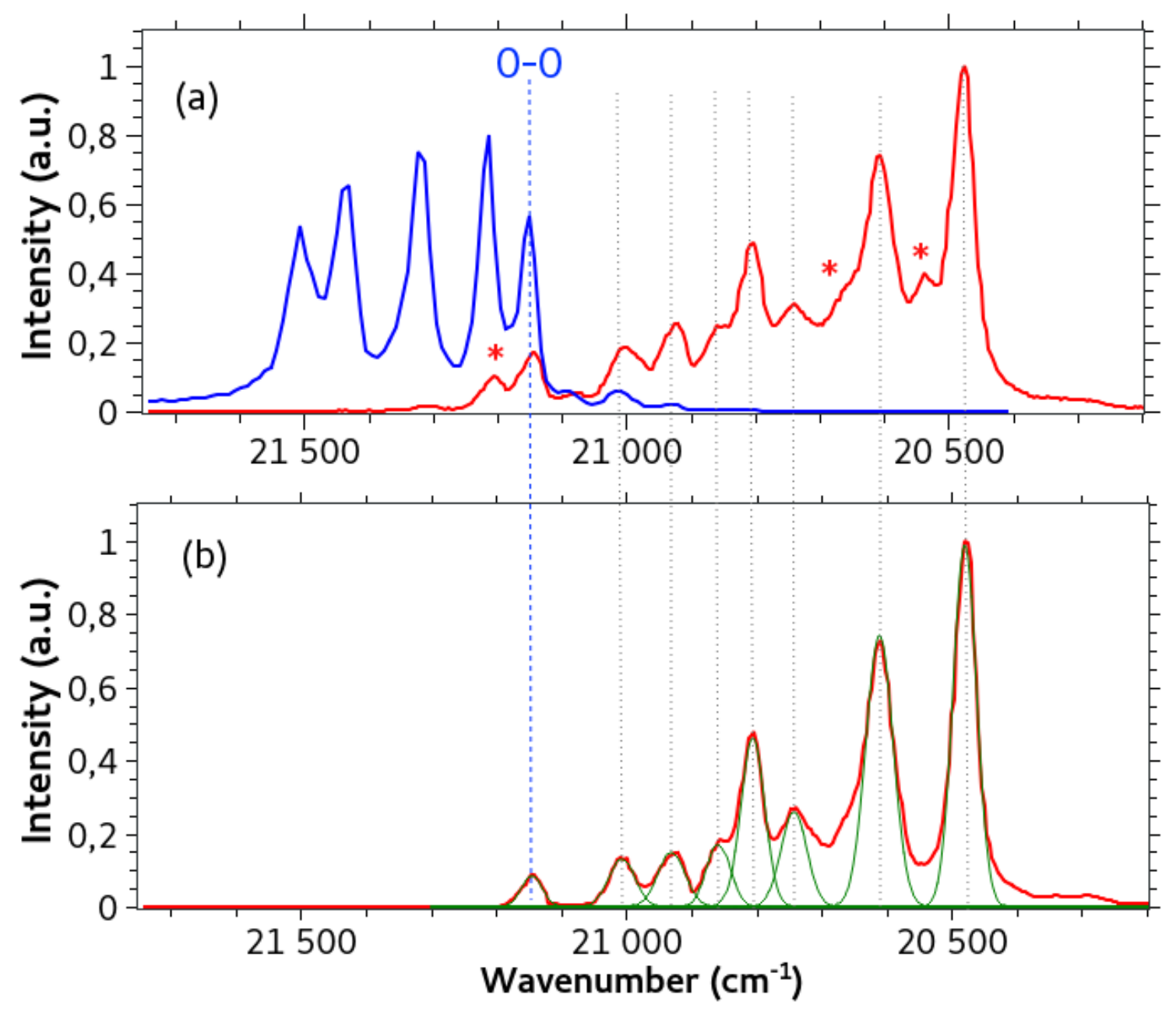

Figure S3: (a) Solid state emission (red) and excitation (blue) spectra of [DyTp $\mathrm{Dp}_{2} \mathrm{Acac}$ ], measured at $77 \mathrm{~K}$. Hot bands are denoted by asterisks. (b) Solid state emission at $10 \mathrm{~K}$. The dashed blue line depicts the $(0,0)$ transition, and the solid green curves correspond to Gaussian fitting of the peaks.

where $\chi_{T}$ is the limit value of susceptibility for $\nu \rightarrow 0, \chi_{S}$ the limit value for $\nu \rightarrow+\infty, \alpha$ the Cole-Cole distortion parameter and $\tau=1 / \nu$ is the relaxation rate. The optimised parameters are gathered in Table S5 in SI, and we represent in Figure S5 the corresponding $\ln \nu=f(1 / T)$ curve. As one can note, the relaxation frequency saturates at low temperature, supporting the hypothesis that QTM is acting. Furthermore, from the $\nu=f(T)$ curve (Figure S1 in SI) it is quite plain that $\nu$ displays a non-linear thermal dependence in the $2 \mathrm{~K}-8 \mathrm{~K}$ range. This suggest the presence of a temperature-dependent relaxation mechanism at higher temperatures. Fitting of these data with a combination of QTM and Orbach (Arrhenius-like) processes proved possible, as shown on Figure $\mathrm{S} 2$, but this yielded an unrealistic energy barrier of 19(1) $\mathrm{K}\left(\right.$ ca. 13.2(7) $\left.\mathrm{cm}^{-1}\right)$, likely too far away from the energy splitting obtained by the means of luminescence spectroscopy.

This, in addition to the observed non linearity in the Arrhenius plot $(\ln \nu=f(1 / T)$ curve), suggests that a non exponential dynamics should be invoked here. Actually, a nice reproduction of the data could be obtained using a power law $\nu=\nu_{Q T M}+a T^{n}$ with $n=2.69(9)$ and $v_{Q T M}=1955(6) \mathrm{Hz}$. Such a low exponent may seem surprising, as in the Raman relaxation one would rather expect a 


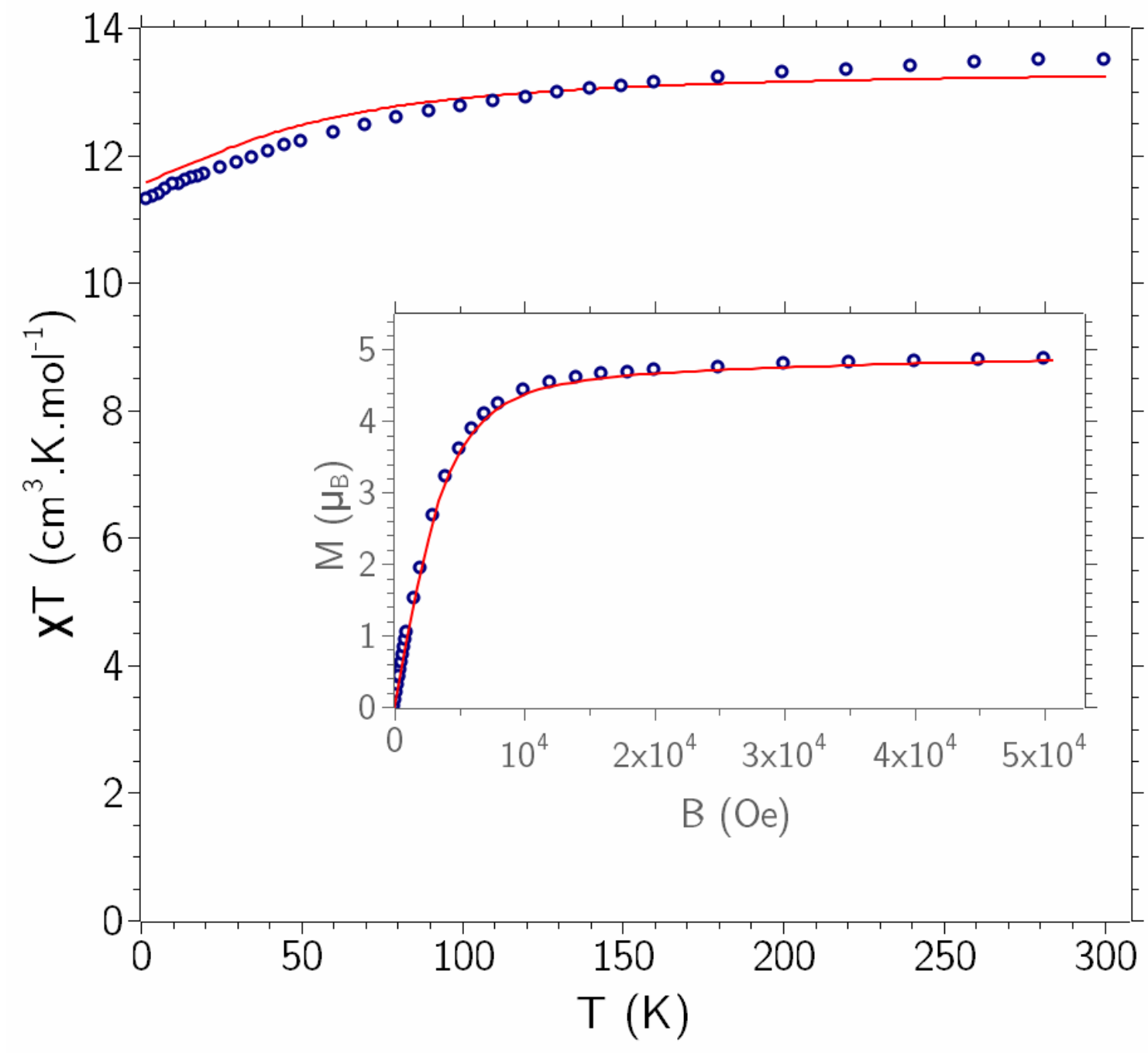

Figure S4: Main figure: Thermal dependence of the $\chi T$ product for [DyTp $\left.{ }_{2} \mathrm{Acac}\right]$, measured under a static field of 1000 Oe between $2 \mathrm{~K}$ and $300 \mathrm{~K}$, on a powder sample (crushed single crystals). Inset: magnetic field dependence of magnetisation at $2 \mathrm{~K}$, between 0 Oe and 50000 Oe. Solid red lines correspond to the ab initio model (-, vide infra), and bullet points to the experimental data (o).

$T^{n}$ temperature dependence with $n=5,7$ or $9 .{ }^{33,48}$ Nevertheless, it is generally assumed that $n$ values between 1 and 6 are acceptable, and most likely stem from deviations from the Debye phonon model. ${ }^{49-51}$ If we fix $n=3$ (closest integer value), we retain a good agreement with the experimental data, and the QTM frequency does only slightly vary (to $v_{Q T M}=1971(4) \mathrm{Hz}$ ).

\section{S5 Ab initio modelling}

In order to gain more insight on the physics beneath the slow relaxation of magnetisation of [DyTp $\mathrm{D}_{2}$ Acac], we then employed SA-CASSCF/RASSI-SO calculations on an isolated complex, basing on the XRD structure (see computational details). ${ }^{52-54}$ Such a theoretical methodology has indeed been very successful in reproducing both the magnetic and luminescence properties of lan- 

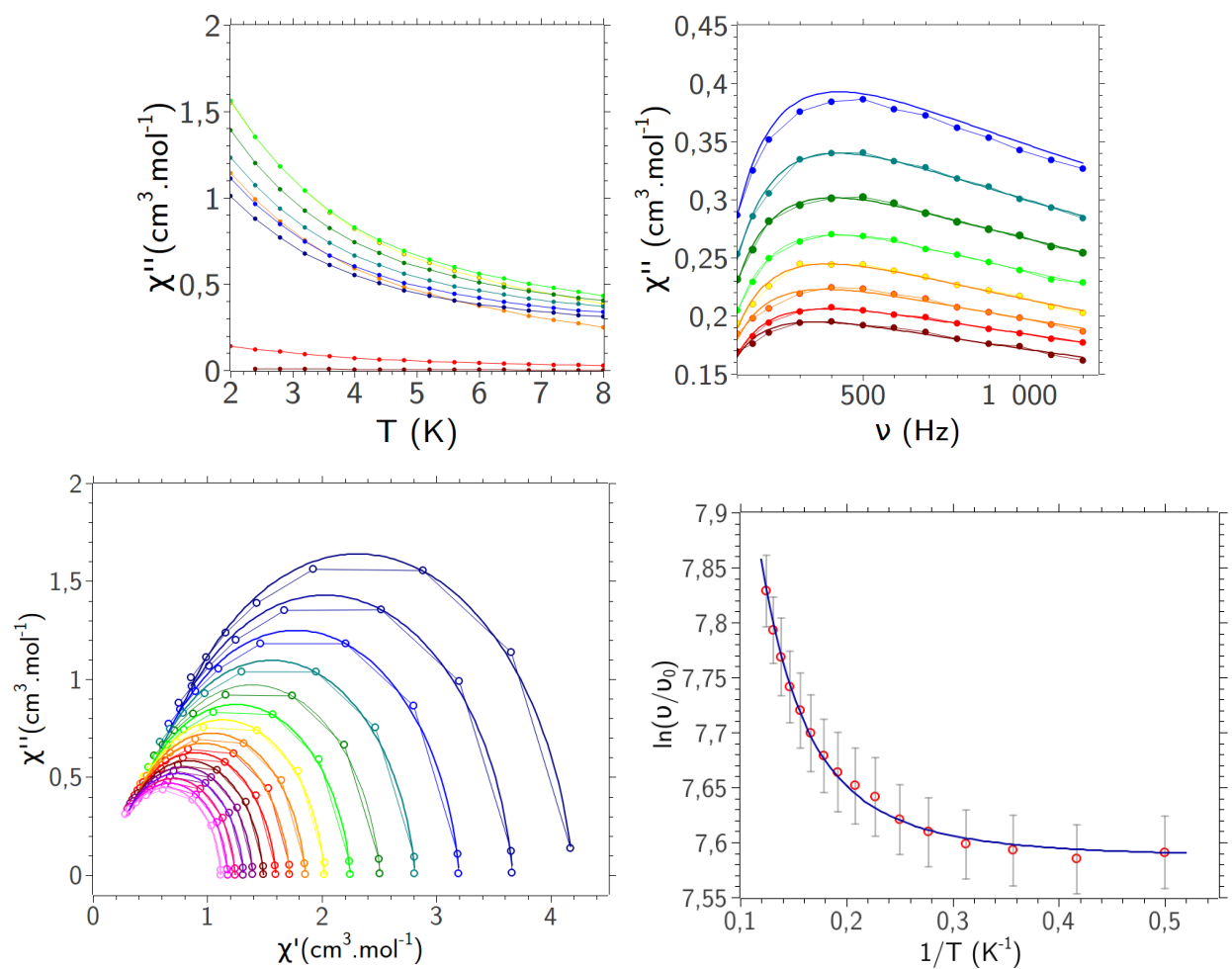

Figure S5: Upper left: $\chi^{\prime \prime}=f(T)$ curves for [DyTp 2 Acac], under a 0 Oe static field, for frequencies ranging between $1 \mathrm{~Hz}$ (brown) and $1400 \mathrm{~Hz}$ (blue). Upper right: $\chi^{\prime \prime}=f(\nu)$ curves for [DyTp $\left.\mathrm{D}_{2} \mathrm{Acac}\right]$, for temperature ranging between $2 \mathrm{~K}$ (blue) and $4.8 \mathrm{~K}$ (dark red). Solid lines correspond to the best fits. Lower left: Cole-Cole $\chi^{\prime \prime}=f\left(\chi^{\prime}\right)$ plot for temperatures ranging from $2 \mathrm{~K}$ (dark blue) to $8 \mathrm{~K}$ (purple). Solid curves correspond to the best fits. Lower right: $\ln \nu=f(1 / T)$ (Arrhenius) plot corresponding to the fits of the $\chi^{\prime \prime}=f(\nu)$ curves, with error bars (gray). The solid line corresponds to $\nu=1971(4)+1.06(2) T^{3}$ (best fit of the $\nu=f(T)$ data).

thanide complexes, noticeably based on Dy(III). ${ }^{8,55,56}$

As one can note from Figure S4, a nice reproduction of the static magnetic properties could be obtained with this model, but interestingly the reproduction of the luminescence data is quite unfortunate. Indeed, though the energies of the three first Kramers doublets (KD) seem reasonably well reproduced, as evidenced in Figure S6, they are quite largely underestimated in the case of the higher sublevels. Interestingly, varying the basis set size did not yield any sensible improvement (see Tables S1 to S3 in $\mathrm{ESI}^{\dagger}$ ), the best agreement being found with the initial basis set.

This forbids any reasoning involving the whole calculated energy diagram and states. However, restricting the discussion to the three lowest levels may provide us with some understanding on our system. The correct reproduction of the static magnetic properties is indeed a sign that at least the lowest energy levels are quite correctly reproduced.

More knowledge can be gained from the decomposition of the wavefunctions of these levels on the basis of the $M_{J}$ states. The lowest KD indeed develops almost solely on the $M_{J}= \pm 15 / 2$ state, which is generally considered a pre-requisite to observe a SMM behaviour with Dy(III)-based complexes. On the other hand, the second and third KD present some $M_{J}$-mixing: the second KD develops principally onto $M_{J}= \pm 13 / 2(80 \%)$ and $M_{J}= \pm 11 / 2(17 \%)$, while the third one develops principally onto $M_{J}= \pm 11 / 2(52 \%), M_{J}= \pm 9 / 2(30 \%)$ and $M_{J}= \pm 13 / 2(8 \%)$. 


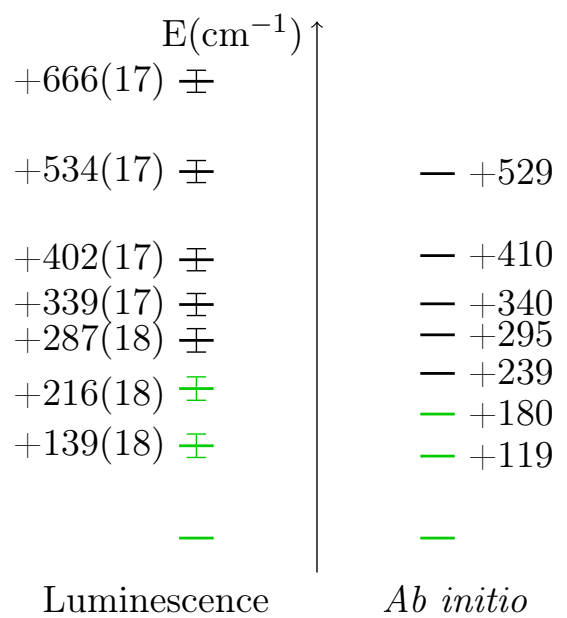

Figure S6: Representation of the energy splitting pattern of the ${ }^{6} H_{15 / 2}$ multiplet of Dy(III), according to the luminescence spectrum (left hand side) and the ab initio data (right hand side).

As such, one may expect a weak quantum tunnelling within the first $\mathrm{KD}$, while it should be stronger in the second and (especially) in the third ones. This is actually retrieved in the computation of Transition Dipole Moments (TDM) (by Single-Aniso ${ }^{57}$ ): within the ground KD, the computed TDM ( $c a .0 .007$ ) is two orders of magnitude lower than in the second (0.062) and third (0.359) KD. Note that this is also consistent with the experimental data: QTM is weak enough here so that we may observe a slow relaxation of magnetisation even in zero field, but it is strong enough to preclude the apparition of maxima in the $\chi^{\prime \prime}=f(T)$ curves.

We gather in Table S2 the other calculated TDM for the three lowest KD of [DyTp $2 \mathrm{Acac}]$. As one can note, transition between states with a similar direction of magnetisation are the most likely, and noteworthy transition between the first and second KD seems to be a highly probable process, thus rendering the associated Orbach or direct mechanisms feasible. Nevertheless, one must keep in mind that TDM calculations do not allow to determine whether a Raman relaxation, involving any two quantum states in the energy diagram, is possible or not. To do so, the computation of the full phonon spectrum and its interactions with the electronic states would be required, and such calculations have only very recently come at hand. ${ }^{17,58,59}$ Judging from the large discrepancy between the AC-SQUID deduced energy barrier and the ab initio or luminescence energy splitting, one may assume that such a Raman relaxation is indeed driving the magnetisation dynamics in our temperature-frequency range, rather than a Orbach mechanism.

Table S2: Calculated Transition Dipole Moment between the 3 lowest $\mathrm{KD}$ of $\left[\mathrm{DyTp}_{2} \mathrm{Acac}\right.$, at the SA-CASSCF/RASSI-SO level, using Single-Aniso. Notation: $1^{+}$refers to the substate of the first $\mathrm{KD}$ with a positive magnetisation (along the $z$ axis), and $1^{-}$to the other substate in the KD (with a negative magnetisation).

\begin{tabular}{l|lllll} 
& $1^{-}$ & $2^{+}$ & $2^{-}$ & $3^{+}$ & $3^{-}$ \\
\hline $1^{+}$ & 0.007 & 1.644 & 0.017 & 0.690 & 0.031 \\
$2^{+}$ & & & 0.062 & 2.397 & 0.088 \\
$3^{+}$ & & & & & 0.359 \\
\hline
\end{tabular}




\section{S6 Conclusions}

In this publication, we reported the complete structural, spectroscopic and magnetic characterisation of a Dy(III) complex, [DyTp ${ }_{2}$ Acac]. Though simple from the point of view of the synthetic process and the structure, this complex shows an intense luminescence of Dy and interesting magnetic properties.

First, we deduced the low energy structure of this complex by direct luminescence measurements. Large energy splittings are observed, which altogether with a rather marked magnetic anisotropy suggested a possible SMM behaviour for [DyTp 2 Acac]. Indeed, we could show that this complex behaves as a genuine single molecule magnet, displaying a slow dynamics of its magnetisation at low temperature. Quite interestingly, a narrow distribution of relaxation rates is observed, which would have agreed with the expected thermal activation mechanism.

However, a study of the relaxation rates thermal dependence, in combination with data from both luminescence spectroscopy and $a b$ initio calculations ruled out any thermal activation mechanism. Conversely, QTM is prevailing at low temperatures and a temperature dependant mechanism, here attributed to Raman process, is controlling the relaxation rate at higher temperatures.

It is worth noticing here that the assignment of the relaxation mechanism only proved possible by the concomitant use of magnetometry, spectroscopy and ab initio calculations. We believe this is another example stressing the efficiency of such coupled studies. ${ }^{20,21,60}$

Also worth mentioning, apart from $\left[\mathrm{DyTp}_{2} \mathrm{Acac}\right]$, a whole family of $\left[\mathrm{LnTp}_{2} \mathrm{Acac}\right]$ complexes can be synthesised with all lanthanide ions, with the same monoclinic structure from lanthanum to dysprosium, while different monoclinic crystal structures were reported for the later lanthanide ions. Such a large family of simple complexes is very advantageous. It indeed offers the possibility to test the usual phenomenological models on lanthanide SMMs on a large set of isostructural complexes. As such, we plan to study them in the close future.

\section{S7 Experimental details.}

\section{S7.1 Materials and methods.}

All the reagents and chemicals were purchased from commercial sources and used without further purification.

\section{S7.2 Synthesis}

$252 \mathrm{mg}$ of $\mathrm{KTp}(1 \mathrm{mmol}), 0.5 \mathrm{~mL}$ of a $1 \mathrm{M}$ solution of $\mathrm{KOH}$ in methanol (0.5 equivalent) and $0.05 \mathrm{~mL}$ of 2,4-pentanedione (AcacH, 0.5 equivalent) are mixed in $10 \mathrm{~mL}$ of methanol. $187 \mathrm{mg}$ of $\mathrm{DyCl}_{3} \cdot 6 \mathrm{H}_{2} \mathrm{O}$ (0.5 equivalents), dissolved in $10 \mathrm{~mL}$ of methanol, are added dropwise to the previous solution. Precipitation occurs during the addition, and the resulting suspension is stirred at room temperature for 10 additional minutes. Afterwards, the solvent is removed under reduced pressure. Then, the solid is extracted in $3 \times 10 \mathrm{~mL}$ of $\mathrm{CH}_{2} \mathrm{Cl}_{2}$, and the filtrate is layered with heptane $(5 \mathrm{~mL})$. It is then left to slowly evaporate. Single crystals are obtained within one week.

\section{S7.3 Single crystal X-Ray diffraction}

X-ray diffracted intensities were collected on a 4-circles XCalibur apparatus (Oxford Diffraction), at room temperature and under a Mo K $\alpha$ radiation $(\lambda=0.7107 \AA)$. Data reduction and absorption correction were computed using CrysAlis. Structure solution was calculated using the charge flipping method using Superflip (as implemented in the software suite Crystals). Missing H atoms were 
obtained using difference Fourier density mapping. All but $\mathrm{H}$ atoms were refined anisotropically by least squares on F using Crystals.

\section{S7.4 Magnetic Measurements}

Powder crystal magnetic susceptibility measurements were carried out on a Quantum Design MPMSXL5 SQUID magnetometer. The sample consisted in ground single crystals of [DyTp 2 Acac], inserted in a Teflon sample holder with two stoppers, in order to prevent any reorientation of the crystallites in the field. The sample holder contribution to magnetisation was corrected accordingly, and diamagnetic contributions were evaluated using Pascal's tables. Powder X-ray diffraction was performed to confirm no structure change occurs during the grinding procedure.

\section{S7.5 Luminescence Measurements}

The luminescence spectra were measured using a Horiba-Jobin Yvon Fluorolog-3 spectrofluorimeter, equipped with a three slit double grating excitation and emission monochromator with dispersions of $2.1 \mathrm{~nm} / \mathrm{mm}$ (1200 grooves $/ \mathrm{mm}$ ). The steady-state luminescence was excited by unpolarized light from a $450 \mathrm{~W}$ xenon CW lamp and detected at an angle of $90^{\circ}$ by a red-sensitive Hamamatsu R928 photomultiplier tube. Spectra were reference corrected for both the excitation source light intensity variation (lamp and grating) and the emission spectral response (detector and grating). $77 \mathrm{~K}$ measurements are performed in quartz tube using liquid nitrogen in a Dewar. $10 \mathrm{~K}$ measurements are performed in quartz tube using Helium in an Oxford Instrument cryostat (OptistatCF2).

\section{S7.6 Ab initio calculations}

$\mathrm{Ab}$ initio calculations were performed using the SA-CASSCF/RASSI-SO approach, as implemented in the MOLCAS 8.0 quantum chemistry suite. ${ }^{61}$ Scalar relativistic corrections were taken into account within the State Averaged Complete Active Space Self Consistent Field (SA-CASSCF) methodology, through the Douglas-Kroll-Hess Hamiltonian, yielding spin-free wavefunctions and energies. ${ }^{52}$ 21 sextet, 224 quartet and 300 doublet roots are considered at this level (9 electrons spanning the $74 f$ orbitals). Then, spin-orbit coupling is added within the Restricted Active Space State Interaction (RASSI-SO) method, which uses the spin-free wavefunctions as basis states. ${ }^{53,54}$ Finally, the magnetic properties, Transition Dipole Moment (TDM) and Landé tensors for the lowest 8 Kramers doublets are calculated using the SINGLE_ANISO ${ }^{57}$ routine.

The calculations were performed on the room temperature X-ray structure. All atoms were

represented by ANO-type basis sets from the ANO-RCC library. ${ }^{62-64}$ The following contractions were used: [8s7p4d3f2g1h] for Dy, [4s3p2d] for the coordinating atoms $(\mathrm{N}, \mathrm{O}),[3 \mathrm{~s} 2 \mathrm{p} 1 \mathrm{~d}]$ for the non-coordinating $\mathrm{C}, \mathrm{N}, \mathrm{B}$ and $\mathrm{O}$ atoms, and [2s] for all the $\mathrm{H}$ atoms.

\section{Conflicts of interest}

There are no conflicts to declare.

\section{Acknowledgements}

OM and FR are grateful to ANR (REDIVALAN ANR-15-CE29-0019-02 and SCOSIMLIGHT ANR13-BS07-0022-01) for financial support. 


\section{References}

[1] Woodruff, D. N.; Winpenny, R. E.; Layfield, R. A. Chem. Rev. 2013, 113, 5110-5148.

[2] Luzon, J.; Sessoli, R. Dalton Trans. 2012, 41, 13556-13567.

[3] Bünzli, J.-C. G.; Eliseeva, S. V. Lanthanide Luminescence; Springer, 2010; pp 1-45.

[4] D'Aléo, A.; Pointillart, F.; Ouahab, L.; Andraud, C.; Maury, O. Coord. Chem. Rev. 2012, 256, 1604-1620.

[5] Cotton, S. Lanthanide and Actinide Chemistry; John Wiley and Sons, 2006; Chapter 5.

[6] Skomski, R. Simple models of Magnetism; Oxford University Press, 2008; Chapter 3.

[7] Vleck, J. H. V. J. Phys. Chem. 1937, 41, 67-80.

[8] Pointillart, F.; Le Guennic, B.; Cador, O.; Maury, O.; Ouahab, L. Acc. Chem. Res. 2015, 11, $2834-2842$.

[9] Cosquer, G.; Pointillart, F.; Jung, J.; Le Guennic, B.; Golhen, S.; Cador, O.; Guyot, Y.; Brenier, A.; Maury, O.; Ouahab, L. Eur. J. Inorg. Chem. 2014, 69-82.

[10] Pointillart, F.; Le Guennic, B.; Golhen, S.; Cador, O.; Maury, O.; Ouahab, L. Chem. Commun. 2013, 49, 615-617.

[11] Cucinotta, G.; Perfetti, M.; Luzon, J.; Etienne, M.; Car, P.-E.; Caneschi, A.; Calvez, G.; Bernot, K.; Sessoli, R. Angew. Chem. Int. Ed. 2012, 51, 1606-1610.

[12] Boulon, M.-E.; Cucinotta, G.; Luzon, J.; Degl'Innocenti, C.; Perfetti, M.; Bernot, K.; Calvez, G.; Caneschi, A.; Sessoli, R. Angew. Chem. Int. Ed. 2013, 52, 350-354.

[13] Long, J.; Vallat, R.; Ferreira, R. A.; Carlos, L. D.; Paz, F. A. A.; Guari, Y.; Larionova, J. Chem. Commun. 2012, 48, 9974-9976.

[14] Bi, Y.; Chen, C.; Zhao, Y.-F.; Zhang, Y.-Q.; Jiang, S.-D.; Wang, B.-W.; Han, J.-B.; Sun, J.-L.; Bian, Z.-Q.; Wang, Z.-M.; Gao, S. Chem. Sci. 2016, 7, 5020-5031.

[15] Al Hareri, M.; Ras Ali, Z.; Regier, J.; Gavey, E. L.; Carlos, L. D.; Ferreira, R. A. S.; Pilkington, M. Inorg. Chem. 2017, 56, 7344-7353.

[16] Al Hareri, M.; Gavey, E. L.; Regier, J.; Ras Ali, Z.; Carlos, L. D.; Ferreira, R. A. S.; Pilkington, M. Chem. Commun. 2016, 52, 11335-11338.

[17] Lunghi, A.; Totti, F.; Sessoli, R.; Sanvito, S. Nat. Commun. 2017, 8, 14620.

[18] Norel, L.; Darago, L. E.; Le Guennic, B.; Chakarawet, K.; Gonzalez, M. I.; Olshansky, J. H.; Rigaut, S.; Long, J. R. Angew. Chem. Int. Ed. 2018, 57, 1933-1938.

[19] Long, J.; Mamontova, E.; Freitas, V.; Luneau, D.; Vieru, V.; Chibotaru, L. F.; Ferreira, R. A. S.; Felix, G.; Guari, Y.; Carlos, L. D.; Larionova, J. RSC Adv. 2016, 6, 108810-108818.

[20] Lescop, C.; Luneau, D.; Rey, P.; Bussière, G.; Reber, C. Inorg. Chem. 2002, 41, 5566-5574.

[21] Bussière, G.; Beaulac, R.; Bélisle, H.; Lescop, C.; Luneau, D.; Rey, P.; Reber, C. Transition Metal and Rare Earth Compounds; Springer, 2004; pp 97-118. 
[22] Jia, J.-H.; Li, Q.-W.; Chen, Y.-C.; Liu, J.-L.; Tong, M.-L. Coord. Chem. Rev. 2017,

[23] Ishikawa, N.; Sugita, M.; Ishikawa, T.; Koshihara, S.-y.; Kaizu, Y. J. Am. Chem. Soc. 2003, 125, 8694-8695.

[24] Rinehart, J. D.; Long, J. R. Chem. Sci. 2011, 2, 2078-2085.

[25] Ahmed, Z.; Iftikhar, K. Inorg. Chem. 2015, 54, 11209-11225.

[26] Bogani, L.; Wernsdorfer, W. Nature Mater. 2008, 7, 179-186.

[27] Affronte, M. J. Mater. Chem. 2009, 19, 1731-1737.

[28] Troiani, F.; Affronte, M. Chem. Soc. Rev. 2011, 40, 3119-3129.

[29] Wang, W.-M.; Duan, W.-W.; Yue, L.-C.; Wang, Y.-L.; Ji, W.-Y.; Zhang, C.-F.; Fang, M.; Wu, Z.-L. Inorg. Chim. Acta 2017, 466, $145-150$.

[30] Lucaccini, E.; Sorace, L.; Perfetti, M.; Costes, J.-P.; Sessoli, R. Chem. Commun. 2014, 50, $1648-1651$.

[31] Pedersen, K. S.; Dreiser, J.; Weihe, H.; Sibille, R.; Johannesen, H. V.; Sørensen, M. A.; Nielsen, B. E.; Sigrist, M.; Mutka, H.; Rols, S.; Bendix, J.; Piligkos, S. Inorg. Chem. 2015, $54,7600-7606$.

[32] Lannes, A.; Luneau, D. Inorg. Chem. 2015, 54, 6736-6743.

[33] Stevens, K. W. H. Rep. Progr. Phys. 1967, 189-226.

[34] Meihaus, K. R.; Rinehart, J. D.; Long, J. R. Inorg. Chem. 2011, 50, 8484-8489.

[35] Trofimenko, S. J. Am. Chem. Soc. 1967, 89, 3170-3177.

[36] Moss, M. A.; Jones, C. J.; Edwards, A. J. Polyhedron 1988, 7, 79 - 81.

[37] Hu, P.; Xiao, F.-P.; Li, Y.; Cao, J.-F.; Chen, Z.-S.; Zhu, L.-L.; Huang, W.-P. Inorg. Chem. Commun. 2017, 84, $207-211$.

[38] Bi, Y.; Guo, Y.-N.; Zhao, L.; Guo, Y.; Lin, S.-Y.; Jiang, S.-D.; Tang, J.; Wang, B.-W.; Gao, S. Chem. Eur. J. 2011, 17, 12476-12481.

[39] Xu, G.-F.; Wang, Q.-L.; Gamez, P.; Ma, Y.; Clerac, R.; Tang, J.; Yan, S.-P.; Cheng, P.; Liao, D.-Z. Chem. Commun. 2010, 46, 1506-1508.

[40] Bünzli, J.-C.; Eliseeva, S. In Comprehensive Inorg. Chem. $\{I I\}$ (Second Edition), second edition ed.; Reedijk, J., Poeppelmeier, K., Eds.; Elsevier: Amsterdam, 2013; pp 339 - 398.

[41] Li, Q.-W.; Liu, J.-L.; Jia, J.-H.; Leng, J.-D.; Lin, W.-Q.; Chen, Y.-C.; Tong, M.-L. Dalton Trans. 2013, 42, 11262-11270.

[42] Yi, X.; Bernot, K.; Pointillart, F.; Poneti, G.; Calvez, G.; Daiguebonne, C.; Guillou, O.; Sessoli, R. Chem. Eur. J. 2012, 18, 11379-11387.

[43] Long, J.; Rouquette, J.; Thibaud, J.-M.; Ferreira, R. A.; Carlos, L. D.; Donnadieu, B.; Vieru, V.; Chibotaru, L. F.; Konczewicz, L.; Haines, J.; Guari, Y.; Larionova, J. Angew. Chem. Int. Ed. 2015, 54, 2236-2240. 
[44] Wu, J.; Cador, O.; Li, X.-L.; Zhao, L.; Le Guennic, B.; Tang, J. Inorg. Chem. 2017, 56, 11211-11219.

[45] Kahn, O. Molecular Magnetism; VCH, 1993.

[46] Sessoli, R.; Powell, A. K. Coord. Chem. Rev. 2009, 253, 2328 - 2341.

[47] Poneti, G.; Bernot, K.; Bogani, L.; Caneschi, A.; Sessoli, R.; Wernsdorfer, W.; Gatteschi, D. Chem. Commun. 2007, 1807-1809.

[48] Abragam, A.; Bleaney, B. Electron Paramagnetic Resonance of Transition Ions; Oxford University Press, 2012; Chapter 10.

[49] Shrivastava, K. Phys. Stat. Sol. (b) 1983, 117, 437-458.

[50] Titos-Padilla, S.; Ruiz, J.; Herrera, J. M.; Brechin, E. K.; Wersndorfer, W.; Lloret, F.; Colacio, E. Inorg. Chem. 2013, 52, 9620-9626.

[51] Costes, J. P.; Titos-Padilla, S.; Oyarzabal, I.; Gupta, T.; Duhayon, C.; Rajaraman, G.; Colacio, E. Inorg. Chem. 2016, 55, 4428-4440.

[52] Roos, B. O.; Taylor, P. R.; Siegbahn, P. E. M. Chem. Phys. 1980, 48, 157-173.

[53] Malmqvist, P. A.; Roos, B. O.; Schimmelpfennig, B. Chem. Phys. Lett. 2002, 357, 230-240.

[54] Malmqvist, P. A.; Roos, B. O. Chem. Phys. Lett. 1989, 155, 189-194.

[55] Gregson, M.; Chilton, N. F.; Ariciu, A.-M.; Tuna, F.; Crowe, I. F.; Lewis, W.; Blake, A. J.; Collison, D.; McInnes, E. J. L.; Winpenny, R. E. P.; Liddle, S. T. Chem. Sci. 2016, 7, 155-165.

[56] Chilton, N. F.; Langley, S. K.; Moubaraki, B.; Soncini, A.; Batten, S. R.; Murray, K. S. Chem. Sci. 2013, 4, 1719-1730.

[57] Chibotaru, L.; Ungur, L. J. Chem. Phys. 2012, 137, 064112.

[58] Goodwin, C. A. P.; Ortu, F.; Reta, D.; Chilton, N.; Mills, D. P. Nat. Lett. 2017, 548, 439-442.

[59] Escalera-Moreno, L.; Suaud, N.; Gaita-Ariño, A.; Coronado, E. J. Phys. Chem. Lett. 2017, 8, 1695-1700.

[60] Lescop, C.; Bussière, G.; Beaulac, R.; Bélisle, H.; Belorizky, E.; Rey, P.; Reber, C.; Luneau, D. J. Phys. Chem. Solid 2004, 65, 773-779.

[61] Aquilante, F.; De Vico, L.; Ferré, N.; Ghigo, G.; Malmqvist, P.-A.; Neogrady, P.; Pedersen, T.; Pitonak, M.; Reiher, M.; Roos, B. O.; Serrano-Andrés, L.; Urban, M.; Veryazov, V.; Lindh, R. J. Comput. Chem. 2010, 31, 224-247.

[62] Roos, B. O.; Lindh, R.; Malmqvist, P.-A.; Veryazov, V.; Widmark, P.-O. J. Phys. Chem. A 2004, 108, 2851-2858.

[63] Roos, B. O.; Lindh, R.; Malmqvist, P.-A.; Veryazov, V.; Widmark, P.-O. J. Phys. Chem. A 2005, 109, 6575-6579.

[64] Roos, B. O.; Lindh, R.; Malmqvist, P.-A.; Veryazov, V.; Widmark, P.-O.; Borin, A. C. J. Phys. Chem. A 2008, 112, 11431-11435. 


\title{
Teach an old molecule new tricks: evidence and rationalisation of a slow dynamics of magnetisation in $\left[\mathrm{DyTp}_{2} \mathrm{Acac}\right]^{\dagger}$
}

\author{
Guégan Frédéric ${ }^{1,2, *, \ddagger}$, Riobé François ${ }^{3}$, Maury Olivier ${ }^{3}$, Jung Julie ${ }^{4}$, Le Guennic Boris ${ }^{4}$, \\ Morell Christophe ${ }^{2}$ and Luneau Dominique ${ }^{1, *}$
}

1 Univ Lyon, Université Claude Bernard Lyon 1, CNRS, Laboratoire des Multimatériaux et Interfaces, F-69622, Villeurbanne, France.

$\ddagger$ Present address: Sorbonne Université, CNRS, Laboratoire de Chimie Théorique, LCT, F-75005 Paris, France.

2 Univ Lyon, Université Claude Bernard Lyon 1, ISA (Institut des Sciences Analytiques de Lyon) - CNRS UMR 5280, F-69100, Villeurbanne, France.

3 Univ Lyon, Ens de Lyon, CNRS UMR 5182, Université Claude Bernard Lyon 1, Laboratoire de Chimie, F69342 Lyon, France.

4 Univ Rennes, CNRS, ISCR (Institut des Sciences Chimiques de Rennes) - UMR 6226, F-35000 Rennes, France. 


\section{Ab initio calculation results}

\section{Basis set dependence}

Basis set dependence of the outcome of the SA-CASSCF/RASSI-SO calculations was studied. ${ }^{1-3}$ ANO basis sets from the ANO-RCC library were used, ${ }^{4-6}$ with the following contractions:

- BS1: [8s7p4d3f2g1h] for Dy, [3s2p1d] for the C, N, B and O atoms, and [2s] for the $\mathrm{H}$ atoms.

- BS2: [8s7p4d3f2g1h] for Dy, [4s3p2d] for the N, O and B atoms, [3s2p1d] for the C, and [2s] for all the $\mathrm{H}$ atoms.

- BS3: [8s7p4d3f2g1h] for Dy, [4s3p2d] for all the B, C, N, O atoms, and [2s] for all the H atoms.

The calculated energy splitting and $M_{J}$ decomposition of the doublets are given in Tables S1 to S3.

Table S1: Energies, Landé tensors and $M_{J}$ decomposition of the ${ }^{6} H_{15 / 2}$ doublets calculated with BS1.

\begin{tabular}{llll} 
Root & $\mathrm{E}\left(\mathrm{cm}^{-1}\right)$ & $g_{X}, g_{Y}, g_{Z}$ & $M_{J}$ decomposition \\
\hline 1 & 0.00 & $(0.01,0.01,19.70)$ & $0.97| \pm 15 / 2\rangle$ \\
2 & 102.99 & $(0.14,0.20,17.22)$ & $0.79| \pm 13 / 2\rangle+0.18| \pm 11 / 2\rangle$ \\
3 & 166.04 & $(0.74,0.94,13.49)$ & $0.46| \pm 11 / 2\rangle+0.40| \pm 9 / 2\rangle$ \\
4 & 226.88 & $(3.05,4.66,9.65)$ & $0.41| \pm 7 / 2\rangle+0.23| \pm 9 / 2\rangle+0.13| \pm 5 / 2\rangle$ \\
5 & 279.74 & $(0.16,4.39,9.78)$ & $0.28| \pm 5 / 2\rangle+0.27| \pm 1 / 2\rangle+0.21| \pm 7 / 2\rangle+0.17| \pm 3 / 2\rangle$ \\
6 & 323.65 & $(1.58,5.17,12.90)$ & $0.36| \pm 3 / 2\rangle+0.30| \pm 5 / 2\rangle+0.23| \pm 1 / 2\rangle$ \\
7 & 411.96 & $(0.02,0.04,19.78)$ & $0.28| \pm 9 / 2\rangle+0.23| \pm 11 / 2\rangle+0.21| \pm 7 / 2\rangle+0.12| \pm 5 / 2\rangle$ \\
8 & 510.27 & $(0.04,0.08,19.49)$ & $0.43| \pm 1 / 2\rangle+0.32| \pm 3 / 2\rangle+0.16| \pm 5 / 2\rangle$ \\
\hline
\end{tabular}

Table S2: Energies, Landé tensors and $M_{J}$ decomposition of the ${ }^{6} H_{15 / 2}$ doublets calculated with BS2.

\begin{tabular}{llll} 
Root & $\mathrm{E}\left(\mathrm{cm}^{-1}\right)$ & $g_{X}, g_{Y}, g_{Z}$ & $M_{J}$ decomposition \\
\hline 1 & 0.00 & 0.010 .0119 .71 & $0.97| \pm 15 / 2\rangle$ \\
2 & 107.45 & 0.130 .1817 .20 & $0.80| \pm 13 / 2\rangle+0.17| \pm 11 / 2\rangle$ \\
3 & 173.08 & 0.640 .8213 .52 & $0.48| \pm 11 / 2\rangle+0.39| \pm 9 / 2\rangle$ \\
4 & 236.13 & 3.044 .519 .63 & $0.41| \pm 7 / 2\rangle+0.25| \pm 9 / 2\rangle+0.12| \pm 5 / 2\rangle$ \\
5 & 291.25 & 0.274 .499 .54 & $0.28| \pm 5 / 2\rangle+0.27| \pm 1 / 2\rangle+0.22| \pm 7 / 2\rangle+0.15| \pm 3 / 2\rangle$ \\
6 & 336.37 & 1.605 .2112 .89 & $0.38| \pm 3 / 2\rangle+0.30| \pm 5 / 2\rangle+0.22| \pm 1 / 2\rangle$ \\
7 & 418.34 & 0.030 .0419 .78 & $0.28| \pm 9 / 2\rangle+0.22| \pm 11 / 2\rangle+0.21| \pm 7 / 2\rangle+0.12| \pm 5 / 2\rangle$ \\
8 & 523.36 & 0.040 .0819 .49 & $0.44| \pm 1 / 2\rangle+0.32| \pm 3 / 2\rangle+0.16| \pm 5 / 2\rangle$ \\
\hline
\end{tabular}


Table S3: Energies, Landé tensors and $M_{J}$ decomposition of the ${ }^{6} H_{15 / 2}$ doublets calculated with BS3.

\begin{tabular}{llll} 
Root & $\mathrm{E}\left(\mathrm{cm}^{-1}\right)$ & $g_{X}, g_{Y}, g_{Z}$ & $M_{J}$ decomposition \\
\hline 1 & 0.00 & 0.010 .0119 .70 & $0.97| \pm 15 / 2\rangle$ \\
2 & 107.60 & 0.120 .1717 .18 & $0.80| \pm 13 / 2\rangle+0.17| \pm 11 / 2\rangle$ \\
3 & 173.05 & 0.690 .8613 .51 & $0.49| \pm 11 / 2\rangle+0.39| \pm 9 / 2\rangle$ \\
4 & 236.30 & 2.884 .429 .67 & $0.41| \pm 7 / 2\rangle+0.26| \pm 9 / 2\rangle+0.12| \pm 5 / 2\rangle$ \\
5 & 292.21 & 9.044 .580 .09 & $0.28| \pm 5 / 2\rangle+0.26| \pm 1 / 2\rangle+0.23| \pm 7 / 2\rangle+0.15| \pm 3 / 2\rangle$ \\
6 & 336.86 & 1.695 .6112 .60 & $0.38| \pm 3 / 2\rangle+0.29| \pm 5 / 2\rangle+0.23| \pm 1 / 2\rangle$ \\
7 & 419.40 & 0.030 .0419 .78 & $0.28| \pm 9 / 2\rangle+0.22| \pm 11 / 2\rangle+0.21| \pm 7 / 2\rangle+0.13| \pm 5 / 2\rangle$ \\
8 & 522.54 & 0.040 .0819 .48 & $0.44| \pm 1 / 2\rangle+0.32| \pm 3 / 2\rangle+0.16| \pm 5 / 2\rangle$ \\
\hline
\end{tabular}




\section{Thermal dependence of the relaxation rate}

As described in the manuscript, the thermal dependance of the magnetisation relaxation rate was obtained through the fitting of the $\chi^{\prime \prime}=f(\nu)$ curves at constant temperature, using

$$
\chi^{\prime \prime}=\left(\chi_{T}-\chi_{S}\right) \frac{(2 \pi \nu \tau)^{1-\alpha} \cos (\pi \alpha / 2)}{1+2(2 \pi \nu \tau)^{1-\alpha} \sin (\pi \alpha / 2)+(2 \pi \nu \tau)^{2-2 \alpha}} .
$$

Fittings were performed using SciDavis, ${ }^{7}$ and the $\chi_{S}$ and $\chi_{T}$ parameters were fixed to the values deduced from the fitting of the Cole-Cole plots at constant temperature. We provide in Table S4 the calculated $\chi_{S}, \chi_{T}$ and $\alpha$ parameters from these fittings, the associated error bars and the $R^{2}$ factor. We then provide in Table S5 the $\alpha$ and $\tau$ parameters obtained via equation 1 , the associated error bars and the agreement factors $R^{2}$. One may note the very good agreement in the $\alpha$ values from both procedures.

Finally, we give in Figure S1 the $\nu=f(T)$ and log-log representation of these data, and also the best fit obtained with $\nu=1971(4)+1.06(2) T^{3}, R^{2}=0.996$. One may note the error bars are rather moderate in the $\nu=f(T)$, and appear much larger in the log-log representation (distortion).

Table S4: Fitted parameters from the Cole-Cole $\chi^{\prime \prime}=f\left(\chi^{\prime}\right)$ plots, associated error bars and agreement factor $R^{2}$ for each temperature.

\begin{tabular}{l|l|l|l|l}
$\mathrm{T}(\mathrm{K})$ & $\alpha \pm \Delta \alpha$ & $\chi_{T} \pm \Delta \chi_{T}\left(\mathrm{~cm}^{3} / \mathrm{mol}^{-1}\right)$ & $\chi_{S} \pm \Delta \chi_{S}\left(\mathrm{~cm}^{3} / \mathrm{mol}^{-1}\right)$ & $R^{2}$ \\
\hline 2.0 & $0.09 \pm 0.01$ & $4.183 \pm 0.008$ & $0.44 \pm 0.04$ & 0.995 \\
2.4 & $0.09 \pm 0.02$ & $3.657 \pm 0.006$ & $0.39 \pm 0.04$ & 0.994 \\
2.8 & $0.09 \pm 0.02$ & $3.193 \pm 0.005$ & $0.35 \pm 0.03$ & 0.995 \\
3.2 & $0.09 \pm 0.02$ & $2.810 \pm 0.004$ & $0.31 \pm 0.03$ & 0.995 \\
3.6 & $0.09 \pm 0.02$ & $2.504 \pm 0.004$ & $0.27 \pm 0.03$ & 0.995 \\
4.0 & $0.09 \pm 0.01$ & $2.247 \pm 0.003$ & $0.25 \pm 0.02$ & 0.996 \\
4.4 & $0.08 \pm 0.02$ & $2.021 \pm 0.003$ & $0.24 \pm 0.02$ & 0.993 \\
4.8 & $0.08 \pm 0.02$ & $1.855 \pm 0.002$ & $0.22 \pm 0.02$ & 0.995 \\
5.2 & $0.07 \pm 0.02$ & $1.717 \pm 0.003$ & $0.21 \pm 0.02$ & 0.993 \\
5.6 & $0.08 \pm 0.01$ & $1.598 \pm 0.002$ & $0.19 \pm 0.02$ & 0.996 \\
6.0 & $0.07 \pm 0.01$ & $1.489 \pm 0.002$ & $0.18 \pm 0.02$ & 0.994 \\
6.4 & $0.07 \pm 0.02$ & $1.398 \pm 0.002$ & $0.17 \pm 0.02$ & 0.994 \\
6.8 & $0.07 \pm 0.01$ & $1.318 \pm 0.001$ & $0.17 \pm 0.01$ & 0.996 \\
7.2 & $0.06 \pm 0.02$ & $1.242 \pm 0.002$ & $0.16 \pm 0.02$ & 0.993 \\
7.6 & $0.06 \pm 0.01$ & $1.180 \pm 0.001$ & $0.16 \pm 0.01$ & 0.996 \\
8.0 & $0.05 \pm 0.01$ & $1.120 \pm 0.001$ & $0.15 \pm 0.01$ & 0.995 \\
\hline
\end{tabular}



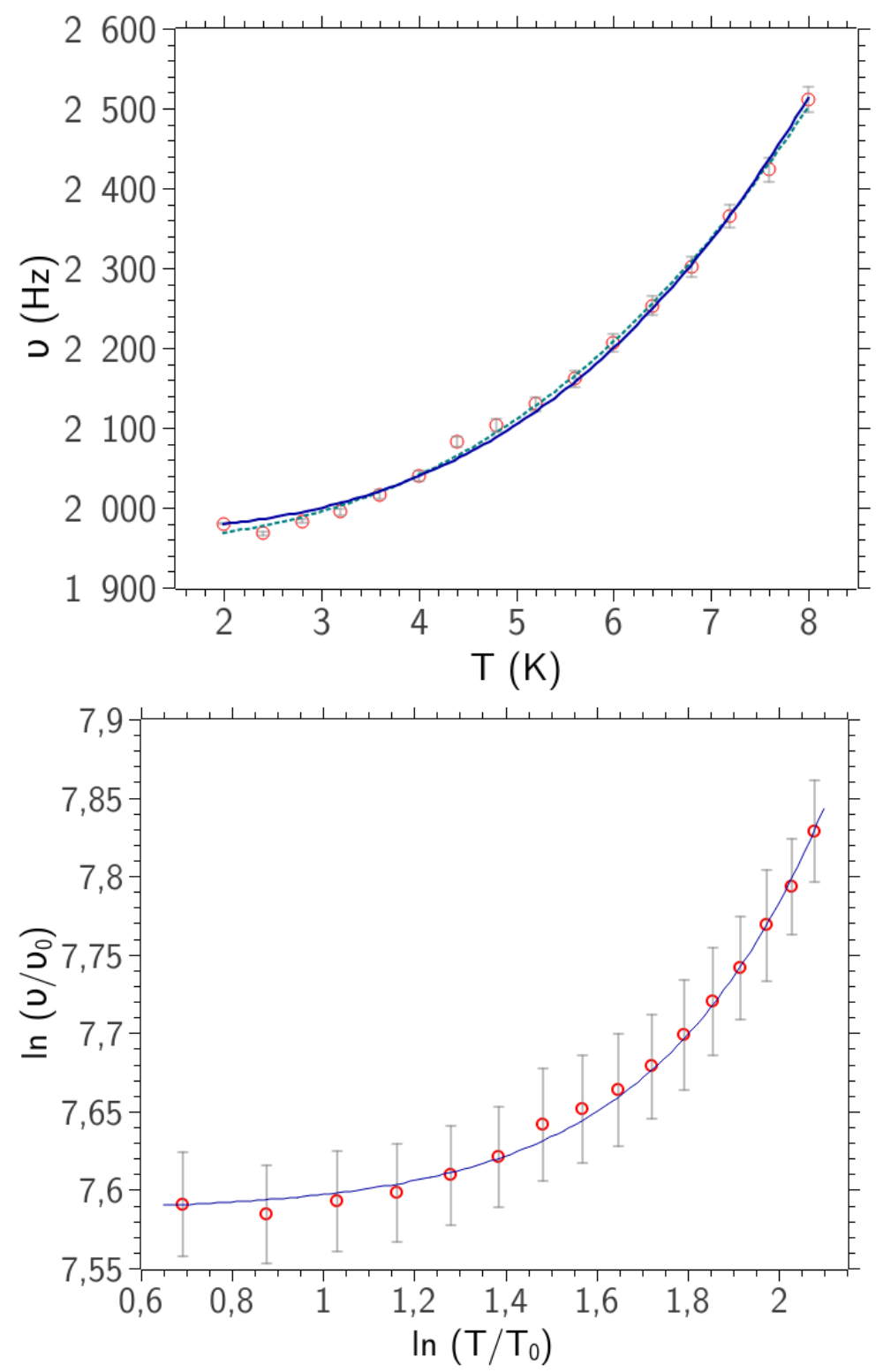

Figure S1: o, thermal dependence of the relaxation frequency as deduced from the fittings of the $\chi^{\prime \prime}=f(\nu)$ curves at constant temperature, with associated error bars (in gray). - , calculated values from the best fit of the $\nu=f(T)$ curve $\left(\nu=1971(4)+1.06(2) T^{3}, R^{2}=0.996\right)$. Top panel: $\nu=f(T)$ plot; bottom panel: log-log plot. 
Table S5: Fitting parameters from equation 1, associated error bars and agreement factor $R^{2}$ for each temperature. Frequencies are also given.

\begin{tabular}{l|l|l|l|l|}
$\mathrm{T}(\mathrm{K})$ & $\alpha \pm \Delta \alpha$ & $\tau \pm \Delta \tau\left(10^{-4} \mathrm{~s}\right)$ & $\nu \pm \Delta \nu(\mathrm{Hz})$ & $R^{2}$ \\
\hline 2.0 & $0.09 \pm 0.01$ & $5.1 \pm 0.2$ & $1980 \pm 67$ & 0.989 \\
2.4 & $0.09 \pm 0.01$ & $5.1 \pm 0.2$ & $1968 \pm 63$ & 0.994 \\
2.8 & $0.09 \pm 0.01$ & $5.0 \pm 0.2$ & $1983 \pm 65$ & 0.993 \\
3.2 & $0.09 \pm 0.01$ & $5.0 \pm 0.2$ & $1995 \pm 63$ & 0.994 \\
3.6 & $0.10 \pm 0.01$ & $5.0 \pm 0.2$ & $2017 \pm 64$ & 0.994 \\
4.0 & $0.09 \pm 0.01$ & $4.9 \pm 0.2$ & $2040 \pm 66$ & 0.994 \\
4.4 & $0.08 \pm 0.02$ & $4.8 \pm 0.2$ & $2082 \pm 76$ & 0.992 \\
4.8 & $0.08 \pm 0.01$ & $4.8 \pm 0.2$ & $2104 \pm 74$ & 0.992 \\
5.2 & $0.08 \pm 0.02$ & $4.7 \pm 0.2$ & $2130 \pm 78$ & 0.992 \\
5.6 & $0.08 \pm 0.01$ & $4.6 \pm 0.2$ & $2161 \pm 74$ & 0.993 \\
6.0 & $0.08 \pm 0.01$ & $4.5 \pm 0.2$ & $2206 \pm 78$ & 0.992 \\
6.4 & $0.07 \pm 0.01$ & $4.4 \pm 0.1$ & $2253 \pm 78$ & 0.993 \\
6.8 & $0.07 \pm 0.01$ & $4.3 \pm 0.1$ & $2302 \pm 76$ & 0.993 \\
7.2 & $0.07 \pm 0.01$ & $4.2 \pm 0.1$ & $2365 \pm 85$ & 0.992 \\
7.6 & $0.06 \pm 0.01$ & $4.1 \pm 0.1$ & $2423 \pm 75$ & 0.994 \\
8.0 & $0.06 \pm 0.01$ & $4.0 \pm 0.1$ & $2511 \pm 83$ & 0.994 \\
\hline
\end{tabular}

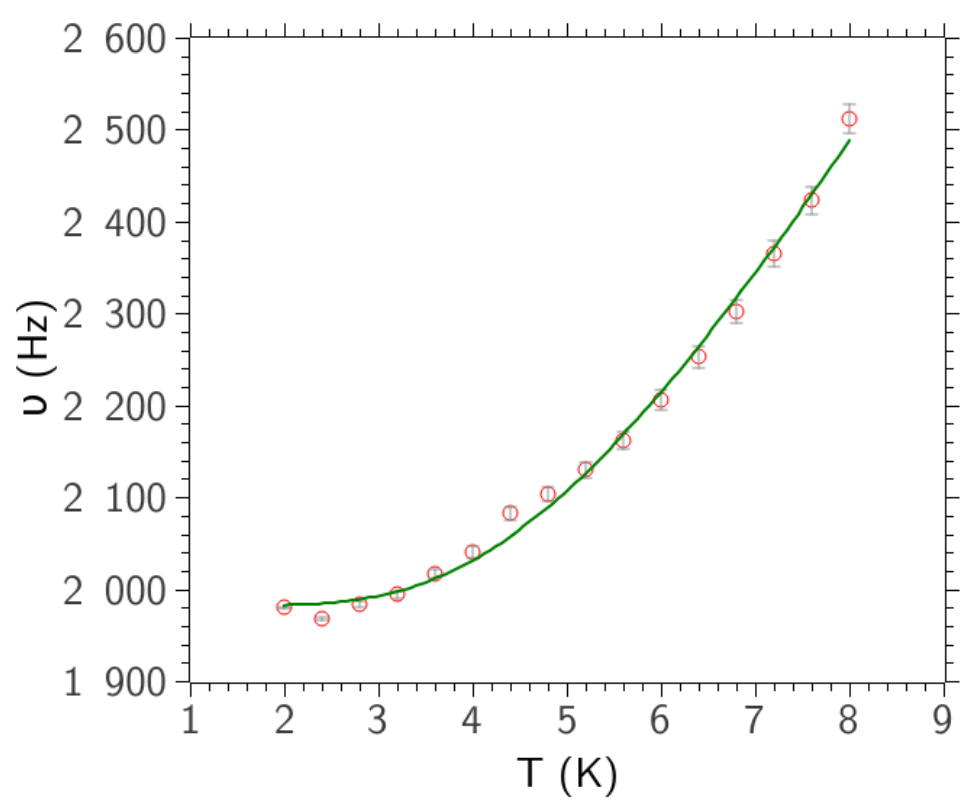

Figure S2: $\circ$, thermal dependence of the relaxation frequency as deduced from the fittings of the $\chi^{\prime \prime}=f(\nu)$ curves at constant temperature, with associated error bars (in gray). - , calculated values from the best fit of the $\nu=f(T)$ curve with $\nu=\left(5.2(6) 10^{3}\right) \exp (-19(1) / T)+1982(7) \mathrm{Hz}$. 


\section{Additionnal AC SQUID data}
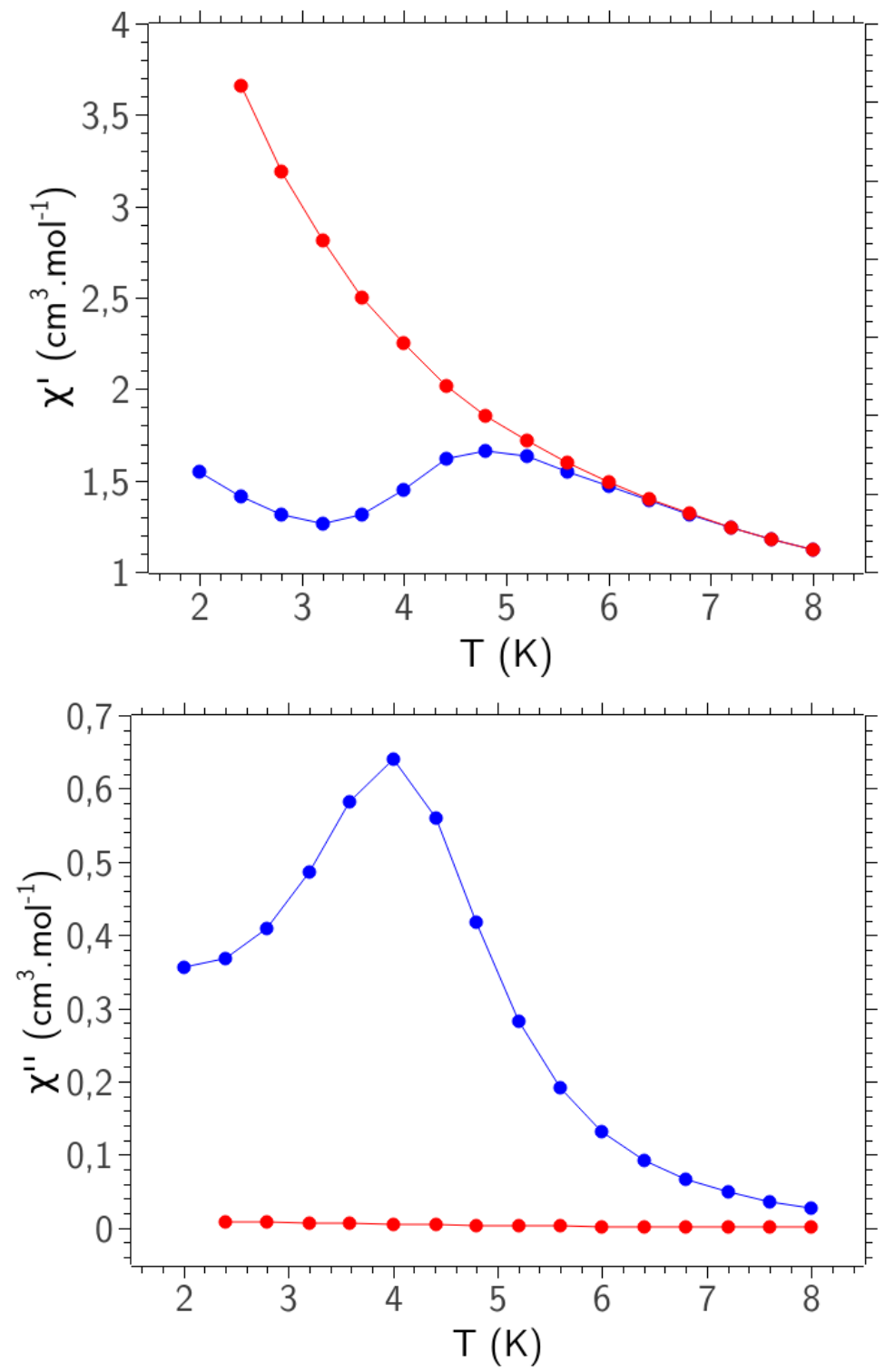

Figure S3: Top: $\chi^{\prime}=f(T)$ at $1 \mathrm{~Hz}$ measured under a static field of 0 Oe (red bullets) and 500 Oe (blue bullets). Bottom: $\chi^{\prime \prime}=f(T)$ at $1 \mathrm{~Hz}$, measured under the same conditions. 


\section{Luminescence decay measurement}

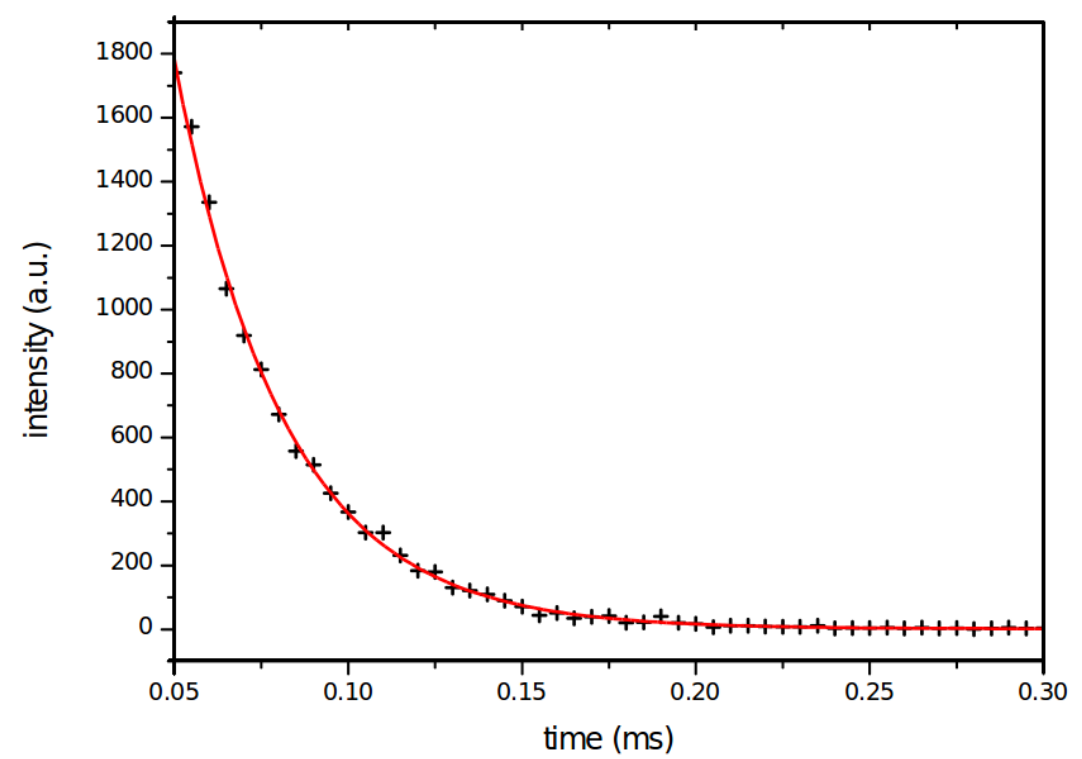

Figure S4: Luminescence decay measurement, under a $350 \mathrm{~nm}$ incident radiation, measured at $580 \mathrm{~nm}$ at ambient temperature. The red solid curve represents the best mono-exponential fit, $I=I_{0} \exp (-t / \tau)+I_{\text {res }}$ with $I_{\text {res }}=1(3), I_{0}=8.8(2) \times 10^{3}$ (arbitrary units) and $\tau=31.4(4) \mathrm{ms}$. 


\section{References}

[1] Roos, B. O.; Taylor, P. R.; Siegbahn, P. E. M. Chem. Phys. 1980, 48, 157-173.

[2] Malmqvist, P. A.; Roos, B. O.; Schimmelpfennig, B. Chem. Phys. Lett. 2002, 357, 230-240.

[3] Malmqvist, P. A.; Roos, B. O. Chem. Phys. Lett. 1989, 155, 189-194.

[4] Roos, B. O.; Lindh, R.; Malmqvist, P.-A.; Veryazov, V.; Widmark, P.-O. J. Phys. Chem. A 2004, 108, $2851-2858$.

[5] Roos, B. O.; Lindh, R.; Malmqvist, P.-A.; Veryazov, V.; Widmark, P.-O. J. Phys. Chem. A 2005, 109, 6575-6579.

[6] Roos, B. O.; Lindh, R.; Malmqvist, P.-A.; Veryazov, V.; Widmark, P.-O.; Borin, A. C. J. Phys. Chem. A 2008, 112, 11431-11435.

[7] Benkert, T.; Franke, K.; Narayanankutty, A.; Pozitron, D.; Standish, R. SciDavis 1.22. http://scidavis.sourceforge.net/, 2017. 